\title{
25 Research Soure \\ Identification of Industrial Sewage Sludge based on Heavy Metal Profiles: A Case Study of Printing and Dyeing Industry
}

Xufeng Zhang ( $\nabla$ zjzhangxufeng@163.com )

Tongji University https://orcid.org/0000-0002-7908-1645

Shuyu Chen

Tongji University

Fangting Ai

Jiaxing-Tongji Environmental Research Institute

Limin Jin

Jiaxing-Tongji Environmental Research Institute

Ningzheng Zhu

Tongji University

Xiang-Zhou Meng

Tongji University

\section{Research Article}

Keywords: Sewage sludge, printing and dyeing industry, heavy metal composition and speciation, characteristic heavy metal, source identification

Posted Date: July 14th, 2021

DOl: https://doi.org/10.21203/rs.3.rs-561952/v1

License: (c) (1) This work is licensed under a Creative Commons Attribution 4.0 International License.

Read Full License

Version of Record: A version of this preprint was published at Environmental Science and Pollution Research on September 26th, 2021. See the published version at https://doi.org/10.1007/s11356-02116569-5. 


\section{Abstract}

The illegal disposal of industrial sewage sludge has caused serious environmental pollution. To develop identification techniques of industrial sewage sludge based on the characteristic fingerprints carried by sewage sludge itself is a promising method that is helpful to clarify the responsibility of illegal enterprises. In this study, heavy metal composition and speciation of sewage sludge from industries (including printing and dyeing industry and other industries) and municipal sewage treatment plant located in eastern China were determined and their performance of classification was evaluated by principal component analysis (PCA) and linear discrimination analysis (LDA). Results showed that heavy metal composition and speciation can be an effective tool for distinguishing sewage sludge between printing and dyeing industry and other industries, with an accuracy rate of $82.9 \%$ and $100 \%$, respectively. Antimony (Sb) and zinc ( $\mathrm{Zn}$ ) are two characteristic heavy metals, which can be used to identity sewage sludge in printing and dyeing sub-industries with an accuracy rate of $90 \%$. The combination of these three methods may be a precise and promising tool for identification of sewage sludge between industries and sub-industries. This study developed a potential method for tracing the industrial sources of sewage sludge and establishing the identification database of industrial sewage sludge, and provided technical support for the government to supervise the illegal dumping and disposal of industrial sewage sludge.

\section{Introduction}

With the development of urbanization and industrialization, water consumption and wastewater production are increasing annually in China. As a result, more and more sewage treatment facilities have been built to meet the increasing demand for wastewater treatment. According to statistics (GOMEP, 2016), a total of 3809 wastewater treatment plants (WWTPs) have been established in China in 2016, which has doubled in the past decade (Xu et al., 2019; Zhou et al., 2019). Similarly, the sewage treatment capacity (i.e., the wastewater treatment rate) of WWTPs has rapidly increased from 25.6 billion $\mathrm{m}^{3} / \mathrm{a}$ (70.2\%) to 46.5 billion $\mathrm{m}^{3}$ /a (94.5\%) (MOHURD, 2017; Zhou et al., 2019). With the increase of sewage treatment capacity, the total sewage sludge production increased significantly. China's sewage sludge production (80\% moisture content) increased from 30 million tonnes in 2012 to 34 million tonnes in 2015, and it is expected to exceed 60 million tonnes in 2020, with an annual growth rate of $15 \%$ (Chen et al., 2019; Feng et al., 2015). The accumulation of sewage sludge will pose growing environmental problems and secondary pollution if treated improperly (Shao et al., 2015).

The environmental impact of industrial sewage sludge is significantly greater than that of municipal sewage sludge because of its high content of toxic and harmful pollutants, such as heavy metals, organic contaminants and pharmaceuticals. Moreover, the yield of industrial sewage sludge is obviously greater than that of municipal sewage sludge. Generally, treatment of 10,000 tonnes of domestic wastewater produces 5-8 tonnes of sewage sludge with $80 \%$ water content, while for industrial wastewater, it produces 10-30 tonnes of sewage sludge. Therefore, the disposal of industrial sewage sludge is the key and difficult point in the effective treatment of sewage sludge. However, in China, the 
combined treatment of municipal wastewater and industrial wastewater brings obstacles to the disposal of sewage sludge (Feng et al., 2015). For example, industrial wastewater contains high concentrations of heavy metals and persistent organic pollutants (POPs), resulting in the sewage sludge produced by the combined system cannot be applied to land as fertilizer or soil conditioner. As high as $35 \%$ of industrial wastewater enters WWTPs in China, while only $20 \%$ of sewage sludge is treated and disposed safely (Feng et al., 2015).

The Chinese government is actively addressing the issue of sewage sludge treatment and disposal, and has proposed that the non-hazardous treatment and disposal efficiency of sewage sludge is expected to be $90 \%$ by 2020 (NDRC and MOHURD, 2017). To achieve this goal, China is actively deploying and building sewage treatment facilities to meet the requirement of the separate treatment of municipal wastewater and industrial wastewater. However, implementation of this proposal will remain a challenge. Many industrial enterprises in China are scattered and not integrated into industrial parks for unified management. Meanwhile, most industrial parks are not equipped with independent wastewater treatment facilities. Furthermore, different from developed countries, China's investment in sewage sludge treatment and disposal (29.4 billion CNY/year) is much lower than that in wastewater treatment (193.8 billion CNY/year) (NDRC and MOHURD, 2017). Low capital investment and marketization operation make enterprises bear most of the pressure of sewage sludge treatment and disposal. Enterprises involved in wastewater discharge are required to set up wastewater treatment facilities or concentrate their wastewater into the wastewater treatment facilities in industrial park for centralized treatment. The sewage sludge produced by the sewage treatment facilities should be safely treated and disposed by enterprises with relevant qualifications, the cost of which is relatively high ( $\sim 00$ yuan per tonnes). To save these costs, some enterprises may dump or bury sewage sludge privately. However, it is difficult for regulators to identify the companies responsible for these violations. One of the feasible methods is to develop an effective and promising identification technology based on the characteristic fingerprints of sewage sludge that can be used to trace the enterprises discharging sewage sludge. The key is to select indicators that can represent different industries. Compared with organic pollutants and pathogens, heavy metals are ubiquitous in industrial sewage sludge, and they cannot be degraded under natural conditions (Dai et al., 2019; Marchenko et al., 2018; Xu et al., 2017). Common treatment methods, e.g. composting, aerobic/anaerobic digestion, cannot remove heavy metals from sewage sludge (Chipasa, 2003; Paulsrud and Nedland, 1997). Likewise, the sludge disposal measures of land application, incineration and landfill can effectively degrade organic pollutants, however, these methods cannot remove heavy metals, leading to their accumulation in the sewage sludge (Cai et al., 2007; Williams, 2005). Moreover, the concentration and composition of heavy metals in sewage sludge discharged by industrial enterprises are quite different due to different production processes and raw and auxiliary materials. Therefore, heavy metals possess the properties of characteristic fingerprints in industrial sewage sludge and we predict heavy metal profiles can be used to identify sewage sludge between different industries, which may be a potential method for tracing the source of illegally discharged industrial sewage sludge. 
In recent years, with the popularity of fast fashion, the fashion industry has achieved unprecedented development. According to the Ellen MacArthur Foundation (EMF) (EMF, 2017), fashion brands produced almost twice as much clothing in 2016 as when the fast fashion phenomenon began (Remy et al., 2016), and the annual growth rate of clothing production is approximately $2 \%$ (Fletcher, 2016). However, the environmental problems caused by the fashion industry have attracted more and more attention and criticism (Niinimäki et al., 2020). At each stage of the industrial chains, the fashion industry has an impact on the environment, such as water pollution in the production and manufacture of textiles, and $\mathrm{CO}_{2}$ emissions in the distribution and consumption of clothing. The fashion industry produces 4-5 billion tonnes of $\mathrm{CO}_{2}$ annually, accounting for 8-10\% of global $\mathrm{CO}_{2}$ emissions (Quantis, 2018; UNCC, 2018), while it consumes 79 trillion litres of water every year (GFA and BCG, 2017), of which textile dyeing contributes $20 \%$ of industrial water pollution (Kant, 2012). However, the globalization of the fashion industry has led to an uneven distribution of these environmental consequences (Niinimäki et al., 2020). Due to the competitive advantages of developing countries in manufacturing and labour costs, textile production and manufacturing has shifted to the developing countries, resulting in the aggravation of environmental pollution in these nations. China has the largest textile production and manufacturing market, ranking first in terms of exports of textiles and clothing, with an annual export value of $\$ 109.9$ billion of textiles and $\$ 158.4$ billion of clothing (Sheng, 2018). As an important part of textile manufacturing, printing and dyeing industry is a traditional pillar of light industry in China, which is mainly located in the eastern coastal areas (including Zhejiang, Jiangsu, Guangdong, Shandong, Fujian and Shanghai). Printing and dyeing wastewater generally has a high concentration of contaminants and a complex chemical composition (including heavy metals, organic pollutants and dyes), and it is difficult to be removed by conventional water treatment technologies (Liang et al., 2013). The major treatment technologies of printing and dyeing wastewater contain physicochemical treatment (such as coagulation or flocculation) and biodegradation, both of which produce a large amount of sewage sludge (Gotvajn and Zagorc-Koncan, 2004). Studies indicated that 1000 tonnes of printing and dyeing wastewater can produce 10 tonnes of printing and dyeing sludge ( $80 \%$ moisture content) (Zhang et al., 2018). According to China Statistical Yearbook on Environment 2016 (NBS, 2016), China produced 20.2 million tonnes of printing and dyeing sludge from 2.02 billion tonnes of printing and dyeing wastewater in 2015 (Ran et al., 2019). The production of a large amount of printing and dyeing sludge is easy to cause environmental risk because of the weak legal consciousness of enterprises and the high cost of sludge treatment (most printing and dyeing enterprises are small and medium-sized enterprises). Therefore, the development of traceability technology of sewage sludge is conducive to the emergency response and accountability for environmental risks caused by illegal disposal of printing and dyeing sludge.

In this study, the heavy metal profiles of industrial and municipal sewage sludge were analyzed to evaluate the application of this technique in identification of printing and dyeing sludge. The aim of the present study was to establish a new and potential method for tracing the industrial origins of sewage sludge and provide technical support for the government to supervise the illegal disposal of sewage sludge. 


\section{Materials And Methods \\ 2.1 Sample collection}

A total of 41 sewage sludge samples were collected from eastern China (including Zhejiang, Jiangsu and Shanghai; Fig. 1), including 23 sewage sludge samples from printing and dyeing industry (PD), 14 sewage sludge samples from other industries, containing metalworking industry (MW), chemical industry $(\mathrm{CH})$, papermaking industry (PM), rubber and plastic industry (RP) and electron industry (EL), and 4 sewage sludge samples from municipal sewage treatment plant (MS) (Table S1, "S" indicates the Supporting Information here and thereafter). The collected sewage sludge samples were wrapped in silver paper and frozen in the refrigerator at $-20^{\circ} \mathrm{C}$. The frozen samples were placed on the stainless steel disc of the freeze-dryer and freeze-dried at $-50{ }^{\circ} \mathrm{C}$ for $48 \mathrm{~h}$. The freeze-dried samples with large particles of impurities (such as stone particles) removed were pulverized by using a glass mortar and pestle, passed through a 60-mesh/inch $(250 \mu \mathrm{m})$ nylon sieve, and then stored in glass bottles under - 20 ${ }^{\circ} \mathrm{C}$ conditions.

\subsection{Sample preparation 2.2.1 Total extraction}

In the present study, the total concentration of heavy metals was extracted by mixed acid digestion method (Yan et al., 2018). Briefly, $0.2 \mathrm{~g}$ of sewage sludge sample was added into the teflon digestion tube, and then $12 \mathrm{~mL}$ of $\mathrm{HCl}^{-\mathrm{HNO}_{3}}(3: 1, \mathrm{v} / \mathrm{v})$ was added. The contents were heated at $130{ }^{\circ} \mathrm{C}$ and evaporated to near dryness. $5 \mathrm{~mL}$ of $\mathrm{HF}$ was added to the digestion tube, heated at $130^{\circ} \mathrm{C}$ for half an hour, and then $8 \mathrm{~mL}$ of $\mathrm{HClO}_{4}$ was added and the temperature was adjusted to $200{ }^{\circ} \mathrm{C}$ until the sample was clarified. $4 \mathrm{~mL}$ of $\mathrm{HNO}_{3}(1: 1, \mathrm{v} / \mathrm{v})$ was added to the digestion tube and heated at $130{ }^{\circ} \mathrm{C}$ until the remaining 1-2 $\mathrm{mL}$ of the sample was obtained. After cooling, the sample was diluted to $10 \mathrm{~mL}$ with $2 \%$ $\mathrm{HNO}_{3}$, and passed through a $0.22 \mu \mathrm{m}$ syringe filter. The filtered sample was transferred to a clean centrifuge tube and stored in a $4{ }^{\circ} \mathrm{C}$ refrigerator.

\subsubsection{Sequential extraction}

In this study, the three-step sequential extraction method proposed by the European Communities Bureau of Reference (BCR) (Rauret et al., 1999) was performed to extract the speciation of heavy metals, the operation process of which was detailed in the previous studies (Chen et al., 2008; Wang et al., 2005). Heavy metals were divided into four fractions, namely acid soluble/exchangeable fraction (F1), reducible fraction (F2), oxidizable fraction (F3) and residual fraction (F4). In addition, we improved the extraction method of F4, and applied the mixed acid digestion method (2.2.1) to extract F4.

\subsection{Sample analysis}


The concentrations of copper $(\mathrm{Cu})$, manganese $(\mathrm{Mn})$, nickel $(\mathrm{Ni})$ and zinc $(\mathrm{Zn})$ were determined using Inductively Coupled Plasma-Atomic Emission Spectroscopy (ICP-AES, Agilent), the wavelengths of which were $327.395 \mathrm{~nm}, 257.610 \mathrm{~nm}, 231.604 \mathrm{~nm}$ and $213.857 \mathrm{~nm}$, respectively. The concentrations of barium $(\mathrm{Ba})$, chromium $(\mathrm{Cr})$, cobalt $(\mathrm{Co})$, plumbum $(\mathrm{Pb})$, antimony $(\mathrm{Sb})$ and vanadium $(\mathrm{V})$ were determined using Inductively Coupled Plasma-Mass Spectrometry (ICP-MS, Agilent). The carrier gas was $\operatorname{Ar}(99.999 \%$ purity). The partial pressure was maintained at 0.6-0.7 Mpa. The regression coefficient $\left(R^{2}\right)$ of the constructed standard curve was greater than 0.999 .

\subsection{Quality assurance and Quality control (QA/QC)}

The QA/QC procedures were performed by analysis of blanks (including method blanks and procedure blanks), replicates and standard reference materials (SRM2781, American National Standards Institute; GBW07404 and GBW07430, National Research Center of Certified Reference Materials of China). Two blank samples and one standard sample (3 replicates for each standard sample) were determined in each batch (20 samples). $20 \%$ of the total samples were performed on parallel experiments ( 2 samples for every 10 samples). During the experiment, the recovery rates of the standard samples ranged from $70-110 \%$, showing a good agreement with the certified values. Meanwhile, the standard deviations between the duplicated samples were within $10 \%$. In the present study, three times of the standard deviation of the blank values was used as limit of detection (LOD), and ten times of that was used as limit of quantitative (LOQ).

\subsection{Statistical analysis}

SPSS 19.0 (SPSS Inc., USA) was applied to data analysis. One-way analysis of variance (ANOVA) was used to test the significance of differences between sewage sludge from different industries based on the contents of heavy metals and the relative percentages of heavy metals, and the significance was set as $p$ $<0.05$. A post hoc test was carried out using the least significant difference (LSD) or Tamhane's T2 to assess significance. Pearson correlation test was performed to analyze the possible relationships among different heavy metals. Principal component analysis (PCA) was employed on the percentages of heavy metal contents and heavy metal forms to reveal the variability of sewage sludge among industries. Linear discriminant analysis (LDA) was used to evaluate whether the different groups could be mathematically distinguished according to heavy metal contents and heavy metal forms for the prediction of industrial source. Due to the limited number of samples, self-verification was used to assess the accuracy of the obtained models.

\section{Results And Discussion}

\subsection{Total heavy metal concentrations}

The heavy metal concentration of printing and dyeing sludge was $3060 \pm 1770 \mathrm{mg} \mathrm{kg}^{-1}$, which was similar to municipal sewage sludge ( $\left.3450 \pm 1770 \mathrm{mg} \mathrm{kg}^{-1}\right)$, but less than sewage sludge from other industries $\left(12,000 \pm 19,500 \mathrm{mg} \mathrm{kg}^{-1}\right)(p>0.05 ; \mathrm{Fig}$. 2$)$. In detail, the heavy metal concentrations of 
sewage sludge in the three printing and dyeing sub-industries (chemical fiber, cotton, and wool, silk and others) were $2820 \pm 1390 \mathrm{mg} \mathrm{kg}^{-1}, 2930 \pm 1590 \mathrm{mg} \mathrm{kg}^{-1}$ and $4400 \pm 3440 \mathrm{mg} \mathrm{kg}^{-1}$, respectively. The most abundant heavy metal in printing and dyeing sludge was $\mathrm{Zn}\left(50.8-5160 \mathrm{mg} \mathrm{kg}^{-1}\right)$, followed by $\mathrm{Mn}$ (72.2-2200 mg kg-1), Sb (3.65-2560 mg kg-1), Cr (25.0-1310 mg kg-1), Cu (5.38-2310 $\left.\mathrm{mg} \mathrm{kg}^{-1}\right)$ and $\mathrm{Ba}\left(28.3-504 \mathrm{mg} \mathrm{kg}^{-1}\right) . \mathrm{V}, \mathrm{Ni}, \mathrm{Pb}$ and Co were relatively scarce, the contents of which were $6.88-241 \mathrm{mg}$ $\mathrm{kg}^{-1}, 8.32-203 \mathrm{mg} \mathrm{kg}^{-1}, 5.23-200 \mathrm{mg} \mathrm{kg}^{-1}$ and 3.85-136 $\mathrm{mg} \mathrm{kg}^{-1}$ (Table S2). It was consistent with the results obtained by Liang et al. (2013), which indicated that the heavy metal contents of printing and dyeing sludge varied greatly. There was a significant difference in Sb content between PD and other industries $(p<0.01)$, as well as MS $(p<0.05)$. However, for other heavy metals, no significant difference was found between these groups. Sb could be used as a characteristic heavy metal in printing and dyeing sludge (Li et al., 2018).

A significant correlation between heavy metals may imply that these elements have a same source or a similar process of transformation and migration (Suresh et al., 2011). The results of Pearson's correlation analysis of heavy metals in printing and dyeing sludge showed that Co had significant positive correlations with $\mathrm{Mn}(r=0.737 ; p<0.01)$ and $\mathrm{Cr}(r=0.507 ; p<0.05)$, and there was a highly significant positive correlation between $\mathrm{Ba}$ and $\mathrm{Cu}(r=0.683 ; p<0.01)$ (Table S3). $\mathrm{Cr}$ and $\mathrm{Co}$ are the main components of metal complex reactive dyes, and $\mathrm{MnO}_{2}$ is an oxidizing agent in neutral dyes (mainly composed of metal complex dyes), therefore, $\mathrm{Cr}$, Co and $\mathrm{Mn}$ have a same source of neutral dyes (Rongqi, 2000). As an important auxiliary agent, copper salt is used in fixing agent and finishing agent, and $\mathrm{Ba}$ is an important component of auxiliary agent used in the textile process, thus, $\mathrm{Cu}$ and $\mathrm{Ba}$ have a same source of auxiliary agent (Ying et al., 2011). However, there were differences in the correlation of heavy metals in the three printing and dyeing sub-industries (Tables $\mathrm{S} 4-\mathrm{S} 6$ ). $\mathrm{Pb}$ had significant positive correlations with $\mathrm{V}(r=0.831 ; p<0.01)$ and $\mathrm{Cu}(r=0.610 ; p<0.05)$, and $\mathrm{Sb}$ had a significant positive correlation with $\mathrm{Ni}(r=0.674 ; p<0.05)$ in $\mathrm{PD}$ (Chemical fiber). Zn had a significant positive correlation with $\mathrm{Ni}(r=0.999 ; p<0.05)$ in PD (Wool, silk and others). While for PD (Cotton), there was no significant positive correlation between heavy metals. The results indicated that the sources and relationships of heavy metals in sewage sludge varied greatly in printing and dyeing industries due to the different materials used.

The percentage of heavy metals in sewage sludge may be more indicative of the characteristics of heavy metals. Table S7 listed the percentage of heavy metal contents in sewage sludge of PD, other industries and MS. The proportions of $\mathrm{Zn}, \mathrm{Mn}, \mathrm{Sb}$ and $\mathrm{Cr}$ in printing and dyeing sludge were relatively large, accounted for $29.4 \pm 19.0 \%, 22.4 \pm 14.6 \%, 18.6 \pm 19.3 \%$ and $11.5 \pm 10.1 \%$, respectively. Meanwhile, the proportions of other heavy metals were less than $10 \%$. The proportions of most heavy metals in the three printing and dyeing sub-industries were similar, but some heavy metals (such as $\mathrm{Cr}, \mathrm{Pb}$ and $\mathrm{Zn}$ ) were different, even more than the differences between different industries (Fig. S1), indicating that the different raw materials used in printing and dyeing industry may cause a great influence on the heavy metal compositions in sewage sludge. The results of one-way ANOVA showed that the percentage of $\mathrm{Sb}$ in PD was significantly different from that of other industries and MS $(p<0.01)$, which was consistent 
with the results of $\mathrm{Sb}$ content, proving that $\mathrm{Sb}$ was a characteristic heavy metal in printing and dyeing sludge.

\subsection{Heavy metal speciation}

The toxicity and mobility of heavy metals depend not only on their total concentration but also on their chemical speciation. The chemical composition of heavy metals can significantly affect their bioavailability and environmental risk. Among them, F1 and F2 have direct eco-toxicity and bioavailability, F3 has potential eco-toxicity and bioavailability, and F4 is stable and has no eco-toxicity and bioavailability (Hu et al., 2011). Therefore, the chemical speciation of heavy metals is one of the characteristic fingerprints of sewage sludge. Tables S8-S11 showed the content of four forms of heavy metals in PD, other industries and MS. The sum of the four fractions was similar to total concentration of heavy metals in original samples, which is consistent with the results of Islam et al. (2017) and Yuan et al. (2011), demonstrating that heavy metals were mainly composed of these four forms. There was no significant difference in most of the heavy metal speciation between PD, other industries and MS, except for three forms of $\mathrm{Sb}$ (acid soluble, oxidizable and residual), reducible Ba and reducible $\mathrm{V}(p<0.05)$ (Fig. S2). Moreover, there was a significant difference in reducible $\mathrm{Zn}$ between printing and dyeing subindustries $(p<0.05)$. The results clarified that the profiles of heavy metal speciation (such as $\mathrm{Sb}, \mathrm{Ba}$ and V) were the characteristic fingerprints in printing and dyeing sludge, and some heavy metal such as Zn, the speciation of which can specify sewage sludge between printing and dyeing sub-industries.

Figure 3 illustrated the percentage of heavy metal forms in sewage sludge of PD, other industries and MS. $\mathrm{Sb}, \mathrm{Pb}, \mathrm{V}, \mathrm{Ba}$ and $\mathrm{Mn}$ were predominantly distributed in $\mathrm{F} 4$, accounting for $61-90 \%$ of the total contents, which was consistent with other studies (Gope et al., 2017; Liang et al., 2013; Lu et al., 2003). Cr and Cu were mainly present in $\mathrm{F} 3$ and $\mathrm{F} 4$, accounting for more than $80 \%$, which was similar to the results of Obrador et al. (2001) and Liang et al. (2013). Co was mainly distributed in F1 and F4, accounting for 32\% and $31 \%$, respectively. Ni was found abundantly in all four fractions (ranged from 17-40\%), which was in agreement with the findings of Fuentes et al. (2008) and Liang et al. (2013). Zn was mainly distributed in F2 (37\%) and F1 (28\%), showing the greatest bioavailability in all metals, which had the highest direct toxicity to the environment (Fytianos and Lourantou, 2004; Jamali et al., 2007). Different from the content of heavy metal speciation, there were significant differences in most of the percentage of heavy metal speciation between PD, other industries and MS, except for Co and Ni. However, there was no significant difference in the percentage of heavy metal speciation between printing and dyeing sub-industries. The results provided evidence of the characteristic fingerprints of the profiles of heavy metal speciation in printing and dyeing sludge.

\subsection{Identification of printing and dyeing sludge 3.3.1 PCA of heavy metal contents and speciation}

Significant differences were found in heavy metal composition and heavy metal speciation among different industries, especially in the percentages of these two indicators, indicating that the percentage 
of heavy metals in sewage sludge can be more effective to trace its industrial source. PCA is arguably the most widely used statistical tool for data analysis for source identification of heavy metals (Wang et al., 2019; Zhao et al., 2020; Zhou et al., 2020). In this study, PCA of percentages of heavy metal contents and heavy metal forms were analyzed to identify sewage sludge between PD, other industries and MS. Figure 4 showed the PCA of percentage of heavy metal contents in PD, other industries and MS. Five significant factors were obtained, accounting for $79.2 \%$ of the total variance (Table S12). Factor 1 explained $19.5 \%$ of variance, and it was highly loaded by Mn and Co, proving that there existed an association between $\mathrm{Mn}$ and $\mathrm{Co}$, which was consistent with the results of Pearson's correlation analysis (Sect. 3.1). Factor 2 explained 17.6\% of variance, and the highest contributions to Factor 2 were $\mathrm{Ba}$ and $\mathrm{Pb}$. Factor 3 yielded $16.4 \%$ of explainable results, with $\mathrm{Sb}$ and $\mathrm{V}$ loading heavily. Factor 4 explained $14.3 \%$ of variance, which was dominated by $\mathrm{Cu}$ and $\mathrm{Zn}$. Factor 5 (11.4\%) was loaded by $\mathrm{Cr}$. The results illustrated that the sewage sludge collected from PD and other industries may be distinguished effectively according to the results of PCA, which indicated that the profiles of percentage of heavy metal contents, combined with PCA, can be used for identification of sewage sludge between different industries. However, the PCA results of percentage of heavy metal contents could not effectively discriminate printing and dyeing sludge from municipal sludge. In addition, the sewage sludge between the three printing and dyeing sub-industries could not be distinguished. Therefore, further analysis was needed to distinguish between sewage sludge from PD and MS, as well as sewage sludge from different printing and dyeing sub-industries.

Figure 5 showed the PCA of percentage of heavy metal forms in PD, other industries and MS. Five significant factors were obtained, accounting for $60.2 \%$ of the total variance, among which factors $1,2,3$, 4 and 5 accounted for $17.9 \%, 14.4 \%, 10.6 \%, 10.0 \%$ and $7.3 \%$, respectively (Table S13). Factor 1 was highly loaded by $\mathrm{V}$ (acid soluble), $\mathrm{Cu}$ (reducible) and $\mathrm{Co}$ (reducible). Factor 2 was highly contributed by $\mathrm{Ni}$ (acid soluble) and $\mathrm{Co}$ (acid soluble and residual). Factor 3 was dominated by $\mathrm{Cr}$ (oxidizable and residual) and $\mathrm{Cu}$ (oxidizable). Factor 4 was heavily loaded by $\mathrm{Ba}$ (reducible) and $\mathrm{Mn}$ (residual). Factor 5 was predominated by $\mathrm{Pb}$ (oxidizable and residual) and $\mathrm{Ba}$ (oxidizable). The results showed that the sewage sludge of PD can be effectively distinguished from that of other industries and MS. We inferred that the profiles of percentage of heavy metal forms, combined with PCA, can be a potential method for identification of sewage sludge between different industries, as well as between industries and municipal sewage treatment plant. However, the sewage sludge between the three printing and dyeing subindustries could not be discriminated according to the results of PCA of percentage of heavy metal forms. Thus, it is necessary to develop another effective method for identification of sewage sludge in printing and dyeing sub-industries.

To evaluate the effect of the obtained models on authentication of sewage sludge between PD, other industries and MS, the classification matrices of percentages of heavy metal contents and heavy metal forms for source prediction were performed by LDA. The method of heavy metal contents was able to correctly classify $82.9 \%$ of the sewage sludge samples (Table S14; Fig. S3), and the accuracy rate of the method of heavy metal forms for identification of industrial origin of sewage sludge was $100 \%$ (Table S14; Fig. S4). The results demonstrated the potential of heavy metal contents and heavy metal forms for 
sewage sludge identification database establishment, and revealed these two methods could be precise and effective techniques for identification of sewage sludge. However, with regard to the identification of sewage sludge between printing and dyeing sub-industry, a new technology should be developed to meet the needs of in-depth identification within the printing and dyeing industry.

\subsubsection{Analysis of characteristic heavy metals}

Heavy metals in industrial sludge mainly come from wastewater discharge during industrial production, and their composition can reflect the characteristics of heavy metals discharge in specific industries. The dominant heavy metals emitted by a specific industry can be regarded as features distinguishing from other industries, which would be called characteristic heavy metals. In the present study, the concentration of $\mathrm{Sb}$ in printing and dyeing sludge $\left(3.65-2560 \mathrm{mg} \mathrm{kg}^{-1}\right)$ was significantly higher than that in other industries $\left(0.07-33.7 \mathrm{mg} \mathrm{kg}^{-1}\right)$, indicating that $\mathrm{Sb}$ could be used as a characteristic heavy metal in the printing and dyeing industry. Moreover, the content of $\mathrm{Sb}$ in the sewage sludge of the three printing and dyeing sub-industries was also different. Briefly, the content of $\mathrm{Sb}$ in the sewage sludge of PD (Chemical fiber) (97.6-1390 $\mathrm{mg} \mathrm{kg}^{-1}$ ) was higher than that in PD (Cotton) (3.65-2560 $\mathrm{mg} \mathrm{kg}^{-1}$ ) and PD (Wool, silk and others) $\left(69.0-444 \mathrm{mg} \mathrm{kg}^{-1}\right)(p<0.05)$. The main reason may be that the production process of polyester fiber used a large number of additives containing antimony compounds, such as antimony ethylene glycoxide, antimony acetate and diantimony trioxide. We speculated that $\mathrm{Sb}$ can be used as a characteristic heavy metal to distinguish sewage sludge between the three printing and dyeing sub-industries. In addition, Zn (reducible) can differentiate sewage sludge between the three printing and dyeing sub-industries, which inferred that $Z n$ can be applied as a characteristic heavy metal to identify sewage sludge between the three printing and dyeing sub-industries. Therefore, two characteristic heavy metals of $\mathrm{Sb}$ and $\mathrm{Zn}$ were used to distinguish the sewage sludge between the three printing and dyeing sub-industries (Fig. 6). The results illustrated that the sewage sludge of PD (Chemical fiber), PD (Cotton) and PD (Wool, silk and others) could be effectively discriminated by the concentrations of Sb and Zn, even though the data of PD (Wool, silk and others) were relatively small (only 3 samples), resulting in an insignificant identification effect. Based on the above results, we predicted that the accuracy rate of identifying the sewage sludge between PD (Chemical fiber) and PD (Cotton) by using the method of characteristic heavy metals ( $\mathrm{Sb}$ and $\mathrm{Zn}$ ) may reach $90 \%$, as a result of two samples belonging to PD (Cotton) were identified as PD (Chemical fiber) (Fig. 6). It was concluded that the application of characteristic heavy metals ( $\mathrm{Sb}$ and $\mathrm{Zn}$ ) could be an effective method for identification of sewage sludge in printing and dyeing sub-industries.

\section{Conclusions}

The results indicated that heavy metal compositions and heavy metal forms, combined with PCA, can be effective methods for identification of printing and dyeing sludge, the accuracy rates of which were $82.9 \%$ and $100 \%$, respectively. In addition, the characteristic heavy metals of Sb and $\mathrm{Zn}$ may be a potential technique to identity sewage sludge in printing and dyeing sub-industries, with an accuracy rate of $90 \%$. It was concluded that the combination of these three methods may be a precise and promising tool for 
identification of sewage sludge between industries and sub-industries. The relevant conclusion of this study develop a potential and effective method for tracing the industrial sources of sewage sludge and establishing the identification database of industrial sludge, and provide technical support for the government to supervise the illegal disposal of industrial sludge. In the future studies, the number of samples will be further increased to improve the database for accurate identification of printing and dyeing sludge. Moreover, the scope of research can be extended from the printing and dyeing industry to other key industries to meet the requirements of government regulation.

\section{Declarations}

\section{Ethical Approval}

Not applicable.

\section{Consent to Participate}

Not applicable.

\section{Consent to Publish}

Not applicable.

\section{Authors Contributions}

Xufeng Zhang: Conceptualization, Methodology, Formal analysis, Investigation, Writing - Original Draft, Writing - Review \& Editing. Shuyu Chen: Methodology, Software, Investigation. Fangting Ai: Software, Formal analysis, Data Curation. Limin Jin: Formal analysis, Visualization. Ningzheng Zhu: Investigation, Validation. Xiang-Zhou Meng: Writing - Review \& Editing, Supervision.

\section{Funding}

The present study was financially supported by the National Science and Technology Major Protects for Water Pollution Control and Treatment (Grant Nos. 2017ZX07201004) and the State Key Laboratory of Pollution Control and Resource Reuse Foundation (NO. PCRRK20016).

\section{Competing Interests}

All authors certify that they have no affiliations with or involvement in any organization or entity with any financial interest or non-financial interest in the subject matter or materials discussed in this manuscript. 


\section{Availability of data and materials}

The datasets used and/or analysed during the current study are available from the corresponding author on reasonable request.

\section{References}

1. Cai, Q.-Y., Mo, C.-H., Wu, Q.-T., Zeng, Q.-Y., Katsoyiannis, A., 2007. Concentration and speciation of heavy metals in six different sewage sludge-composts. Journal of Hazardous Materials 147, 10631072.

2. Chen, G., Wang, X., Li, J., Yan, B., Wang, Y., Wu, X., Velichkova, R., Cheng, Z., Ma, W., 2019. Environmental, energy, and economic analysis of integrated treatment of municipal solid waste and sewage sludge: A case study in China. Science of the Total Environment 647, 1433-1443.

3. Chen, M., Li, X.-m., Yang, Q., Zeng, G.-m., Zhang, Y., Liao, D.-X., Liu, J.-j., Hu, J.-m., Guo, L., 2008. Total concentrations and speciation of heavy metals in municipal sludge from Changsha, Zhuzhou and Xiangtan in middle-south region of China. Journal of Hazardous Materials 160, 324-329.

4. Chipasa, K.B., 2003. Accumulation and fate of selected heavy metals in a biological wastewater treatment system. Waste Management 23, 135-143.

5. Dai, Q., Ma, L., Ren, N., Ning, P., Guo, Z., Xie, L., 2019. Research on the variations of organics and heavy metals in municipal sludge with additive acetic acid and modified phosphogypsum. Water Research 155, 42-55.

6. EMF, 2017. A new textiles economy: Redesigning fashion's future. Ellen MacArthur Foundation, https://www.ellenmacarthurfoundation.org/assets/downloads/publications/A-New-TextilesEconomy_Full-Report.pdf.

7. Feng, L., Luo, J., Chen, Y., 2015. Dilemma of Sewage Sludge Treatment and Disposal in China. Environmental Science \& Technology 49, 4781-4782.

8. Fletcher, K., 2016. Craft of Use: Post-Growth Fashion. Routledge.

9. Fuentes, A., Llorens, M., Saez, J., Aguilar, M.I., Ortuno, J.F., Meseguer, V.F., 2008. Comparative study of six different sludges by sequential speciation of heavy metals. Bioresource Technology 99, 517-525.

10. Fytianos, K., Lourantou, A., 2004. Speciation of elements in sediment samples collected at lakes Volvi and Koronia, N. Greece. Environment International 30, 11-17.

11. GFA, BCG, 2017. Pulse of the fashion industry. Global Fashion Agenda/The Boston Consulting Group, https://www.globalfashionagenda.com/wp-content/uploads/2017/2005/Pulse-of-theFashion-Industry_2017.pdf.

12. GOMEP, 2016. 2016 National Key Monitoring Enterprises of Wastewater Treatment Plants. General Office of Ministry of Environmental Protection of the People's Republic of China.

13. Gope, M., Masto, R.E., George, J., Hoque, R.R., Balachandran, S., 2017. Bioavailability and health risk of some potentially toxic elements ( $\mathrm{Cd}, \mathrm{Cu}, \mathrm{Pb}$ and $\mathrm{Zn}$ ) in street dust of Asansol, India. Ecotoxicology 
and Environmental Safety 138, 231-241.

14. Gotvajn, A.Z., Zagorc-Koncan, J., 2004. Characterization of textile wastewater: Its environmental impact and biotreatability. Chemical and Biochemical Engineering Quarterly 18, 309-315.

15. Hu, X., Zhang, Y., Luo, J., Wang, T., Lian, H., 2011. Total concentrations and fractionation of heavy metals in road-deposited sediments collected from different land use zones in a large city (Nanjing), China. Chemical Speciation and Bioavailability 23, 46-52.

16. Islam, M.S., Ahmed, M.K., Raknuzzaman, M., Habibullah-Al-Mamun, M., Kundu, G.K., 2017. Heavy metals in the industrial sludge and their ecological risk: A case study for a developing country. Journal of Geochemical Exploration 172, 41-49.

17. Jamali, M.K., Kazi, T.G., Afridi, H.I., Arain, M.B., Jalbani, N., Memon, A.R., 2007. Speciation of heavy metals in untreated domestic wastewater sludge by time saving BCR sequential extraction method. Journal of Environmental Science and Health Part a-Toxic/Hazardous Substances \& Environmental Engineering 42, 649-659.

18. Kant, R., 2012. Textile dyeing industry: An environmental hazard. Natural Science 41, 22-26.

19. Li, W., Zhou, S., Zou, J., Fang, R., Jiang, T., Bao, Y., Shi, H., 2018. Analysis on the origin of antimony pollution in urban sewage treatment plant mainly engaged in printing and dyeing wastewater. Journal of Zhejiang University. Sciences Edition 45, 569-575.

20. Liang, X., Ning, X.-a., Chen, G., Lin, M., Liu, J., Wang, Y., 2013. Concentrations and speciation of heavy metals in sludge from nine textile dyeing plants. Ecotoxicology and Environmental Safety 98, 128134.

21. Lu, Y., Gong, Z.T., Zhang, G.L., Burghardt, W., 2003. Concentrations and chemical speciations of Cu, $\mathrm{Zn}, \mathrm{Pb}$ and $\mathrm{Cr}$ of urban soils in Nanjing, China. Geoderma 115, 101-111.

22. Marchenko, O., Demchenko, V., Pshinko, G., 2018. Bioleaching of heavy metals from sewage sludge with recirculation of the liquid phase: A mass balance model. Chemical Engineering Journal 350, 429-435.

23. MOHURD, 2017. China Urban-Rural Construction Statistical Yearbook 2017. Ministry of Housing and Urban-Rural Development of the People's Republic of China, http://www.mohurd.gov.cn/xytj/tjzljsxytjgb/.

24. NBS, 2016. China Statistical Yearbook on Environment 2016. National Bureau of Statistics of the People's Republic of China, http://www.stats.gov.cn/tjsj./tjcbw/201706/t20170621_21505831.html.

25. NDRC, MOHURD, 2017. The thirteenth five-year plan for the construction of urban sewage treatment and recycling facilities. National Development and Reform Commission of the People's Republic of China/Ministry of Housing and Urban-Rural Development of the People's Republic of China, http://www.gov.cn/xinwen/2017-2001/2023/content_5162482.htm.

26. Niinimäki, K., Peters, G., Dahlbo, H., Perry, P., Rissanen, T., Gwilt, A., 2020. The environmental price of fast fashion. Nature Reviews Earth \& Environment volume 1, 189-200.

27. Obrador, A., Rico, M.I., Alvarez, J.M., Novillo, J., 2001. Influence of thermal treatment on sequential extraction and leaching behaviour of trace metals in a contaminated sewage sludge. Bioresource 
Technology 76, 259-264.

28. Paulsrud, B., Nedland, K.T., 1997. Strategy for land application of sewage sludge in Norway. Water Science and Technology 36, 283-290.

29. Quantis, 2018. Measuring fashion: insights from the environmental impact of the global apparel and footwear industries. Full report and methodological considerations, https://quantisintl.com/measuring-fashion-report.

30. Ran, C., Liu, Y., Siddiqui, A.R., Siyal, A.A., Mao, X., Kang, Q., Fu, J., Ao, W., Dai, J., 2019. Pyrolysis of textile dyeing sludge in fluidized bed: Analysis of products, and migration and distribution of heavy metals. Journal of Cleaner Production 241.

31. Rauret, G., Lopez-Sanchez, J.F., Sahuquillo, A., Rubio, R., Davidson, C., Ure, A., Quevauviller, P., 1999. Improvement of the BCR three step sequential extraction procedure prior to the certification of new sediment and soil reference materials. Journal of Environmental Monitoring 1, 57-61.

32. Remy, N., Speelman, E., Swartz, S., 2016. Style that's sustainable: a new fast-fashion formula. McKinsey \& Company, https://www.mckinsey.com/business-functions/sustainability/ourinsights/style-thats-sustainable-a-new-fast-fashion-formula.

33. Rongqi, C., 2000. Heavy metal residuals on textiles (II). Dyeing and Finishing 26, 41-48. (in Chinese).

34. Shao, J., Yuan, X., Leng, L., Huang, H., Jiang, L., Wang, H., Chen, X., Zeng, G., 2015. The comparison of the migration and transformation behavior of heavy metals during pyrolysis and liquefaction of municipal sewage sludge, paper mill sludge, and slaughterhouse sludge. Bioresource Technology $198,16-22$.

35. Sheng, L., 2018. Changing trends in world textile and apparel trade. just-style, https://www.juststyle.com/analysis/changing-trends-in-world-textile-and-apparel-trade_id134353.aspx.

36. Suresh, G., Ramasamy, V., Meenakshisundaram, V., Venkatachalapathy, R., Ponnusamy, V., 2011. Influence of mineralogical and heavy metal composition on natural radionuclide concentrations in the river sediments. Applied Radiation and Isotopes 69, 1466-1474.

37. UNCC, 2018. UN helps fashion industry shift to low carbon. United Nations Climate Change, https://unfccc.int/news/un-helps-fashion-industry-shift-to-low-carbon.

38. Wang, C., Hu, X., Chen, M.L., Wu, Y.H., 2005. Total concentrations and fractions of Cd, Cr, Pb, Cu, Ni and $\mathrm{Zn}$ in sewage sludge from municipal and industrial wastewater treatment plants. Journal of Hazardous Materials 119, 245-249.

39. Wang, J., Su, J., Li, Z., Liu, B., Cheng, G., Jiang, Y., Li, Y., Zhou, S., Yuan, W., 2019. Source apportionment of heavy metal and their health risks in soil-dustfall-plant system nearby a typical non-ferrous metal mining area of Tongling, Eastern China. Environmental Pollution 254.

40. Williams, P.T., 2005. Waste Treatment and Disposal. John Wiley \& Sons, New York.

41. Xu, Y., Naidoo, A.R., Zhang, X.-F., Meng, X.-Z., 2019. Optimizing sampling strategy for Chinese National Sewage Sludge Survey (CNSSS) based on urban agglomeration, wastewater treatment process, and treatment capacity. Science of the Total Environment 696. 
42. Xu, Y., Zhang, C., Zhao, M., Rong, H., Zhang, K., Chen, Q., 2017. Comparison of bioleaching and electrokinetic remediation processes for removal of heavy metals from wastewater treatment sludge. Chemosphere 168, 1152-1157.

43. Yan, G., Mao, L., Liu, S., Mao, Y., Ye, H., Huang, T., Li, F., Chen, L., 2018. Enrichment and sources of trace metals in roadside soils in Shanghai, China: A case study of two urban/rural roads. Science of the Total Environment 631-632, 942-950.

44. Ying, C., Huagen, D., Jingjing, S., 2011. Ecological problems and countermeasures of printing and dyeing auxiliaries. Jiangsu Silk 40, 29-31. (in Chinese).

45. Yuan, X., Huang, H., Zeng, G., Li, H., Wang, J., Zhou, C., Zhu, H., Pei, X., Liu, Z., Liu, Z., 2011. Total concentrations and chemical speciation of heavy metals in liquefaction residues of sewage sludge. Bioresource Technology 102, 4104-4110.

46. Zhang, H., Gao, Z., Liu, Y., Ran, C., Mao, X., Kang, Q., Ao, W., Fu, J., Li, J., Liu, G., Dai, J., 2018. Microwave-assisted pyrolysis of textile dyeing sludge, and migration and distribution of heavy metals. Journal of Hazardous Materials 355, 128-135.

47. Zhao, Y.-p., Wu, R., Cui, J.-I., Gan, S.-c., Pan, J.-C., Guo, P.-r., 2020. Improvement of water quality in the Pearl River Estuary, China: a long-term (2008-2017) case study of temporal-spatial variation, source identification and ecological risk of heavy metals in surface water of Guangzhou. Environmental Science and Pollution Research.

48. Zhou, L., Liu, G., Shen, M., Hu, R., Liu, Y., 2020. Source identification of heavy metals and stable carbon isotope in indoor dust from different functional areas in Hefei, China. Science of the Total Environment 710.

49. Zhou, Y., Meng, J., Zhang, M., Chen, S., He, B., Zhao, H., Li, Q., Zhang, S., Wang, T., 2019. Which type of pollutants need to be controlled with priority in wastewater treatment plants: Traditional or emerging pollutants? Environment International 131.

\section{Figures}




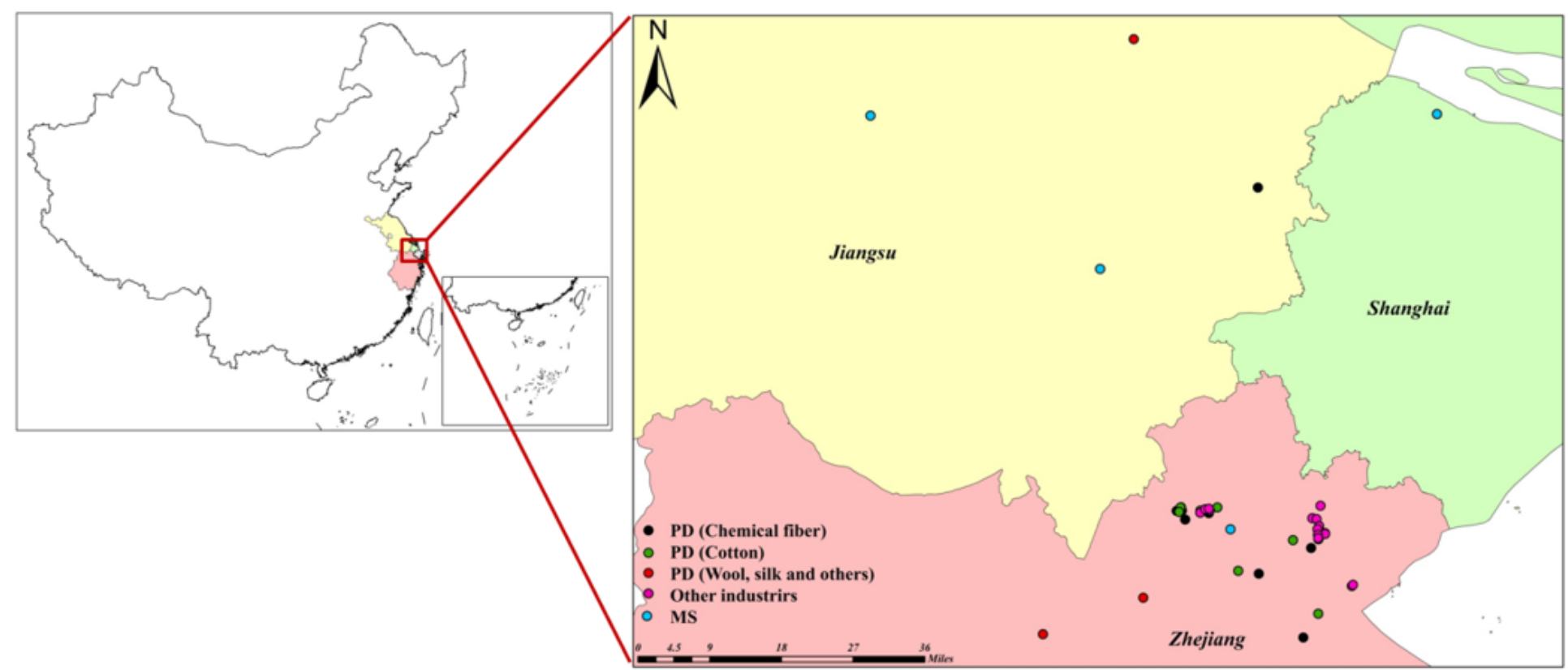

\section{Figure 1}

Sampling locations of sewage sludge in eastern China. PD and MS represent printing and dyeing industry and municipal sewage treatment plant, respectively. 


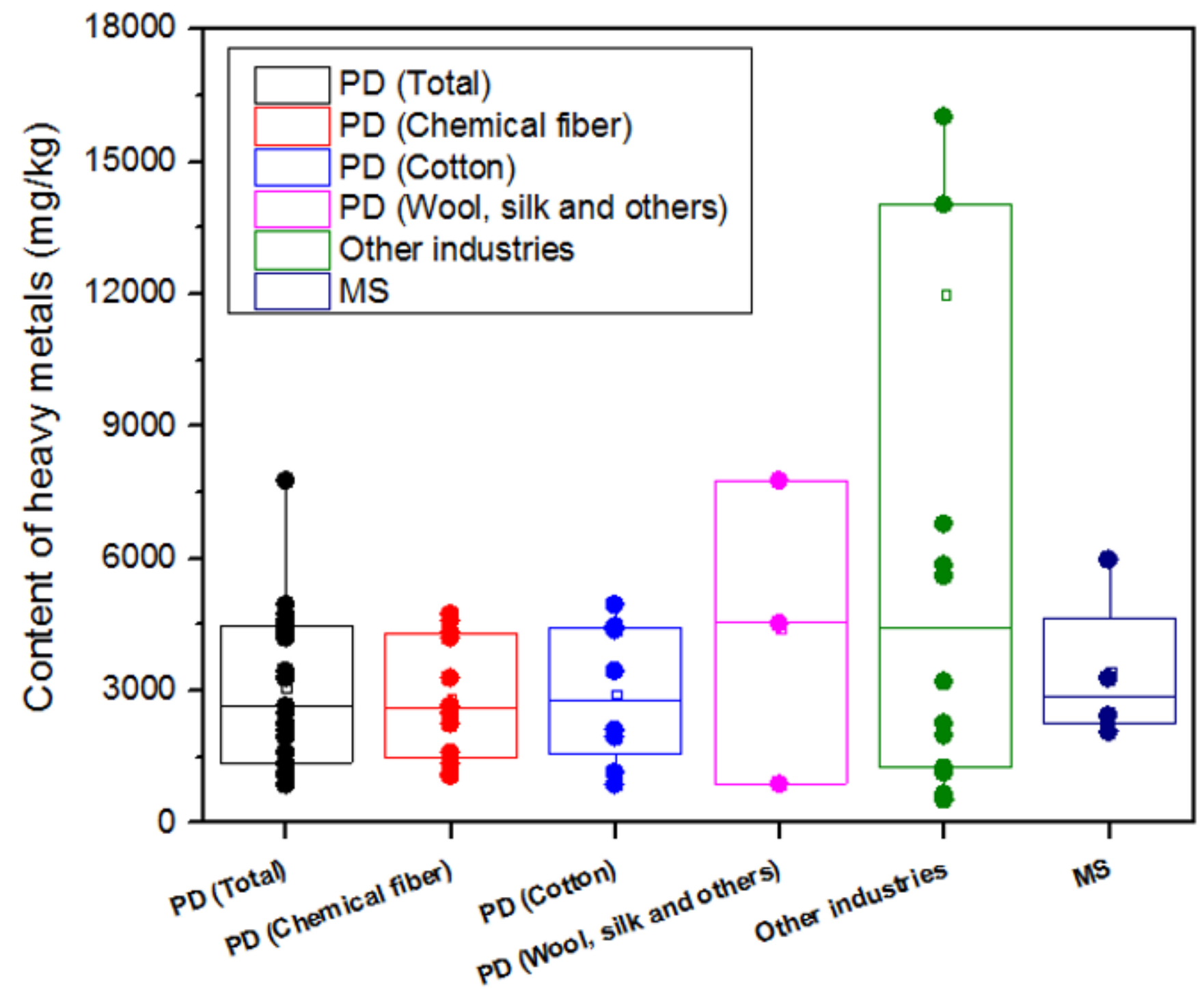

Figure 2

Box plot of heavy metal contents in industrial and municipal sewage sludge ( $\mathrm{mg} \mathrm{kg}-1)$. PD and MS represent printing and dyeing industry and municipal sewage treatment plant, respectively. 
$\mathrm{Ba}$

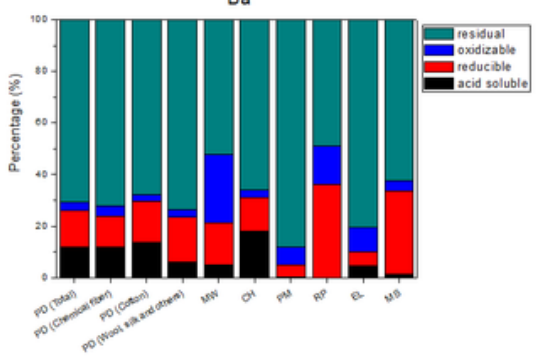

$\mathrm{Cr}$

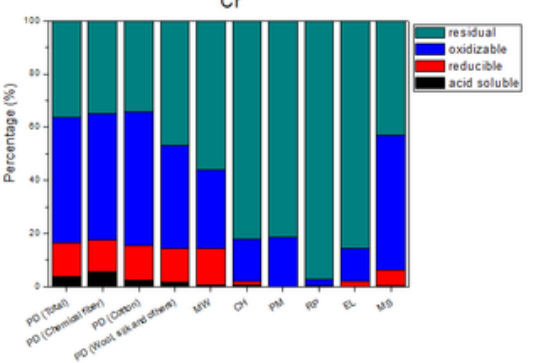

$\mathrm{Mn}$

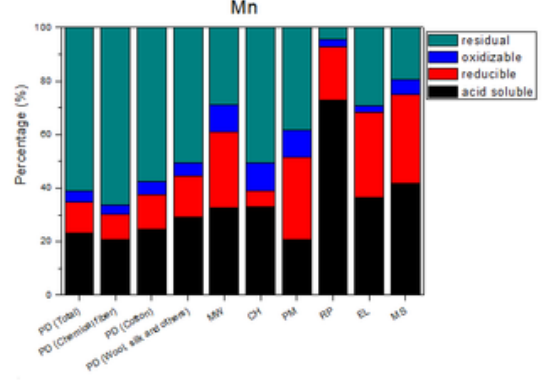

$\mathrm{Pb}$

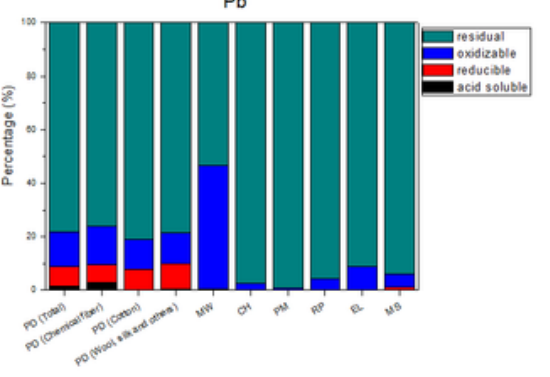

$\mathrm{V}$

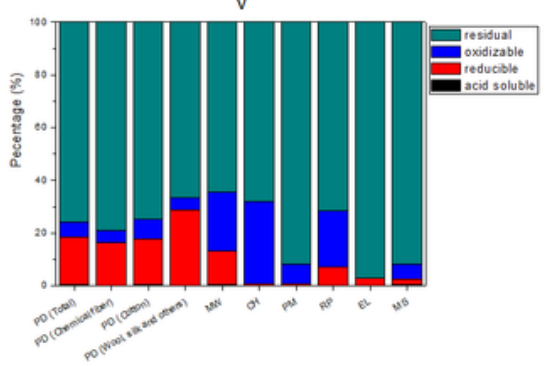

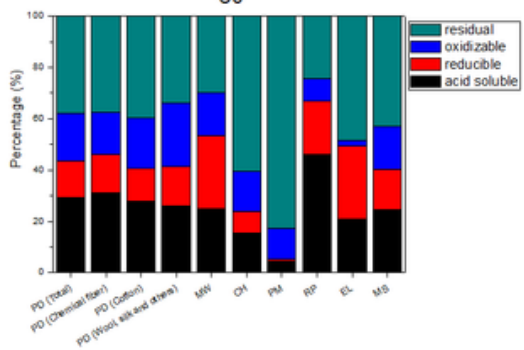

$\mathrm{Cu}$

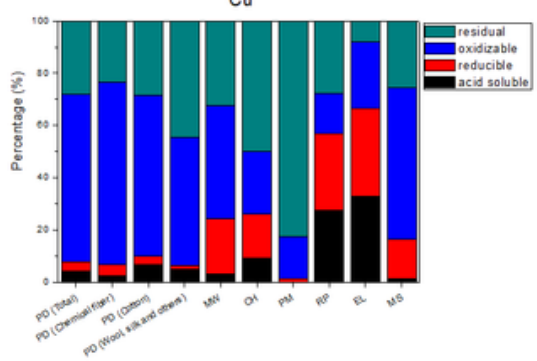

$\mathrm{Ni}$
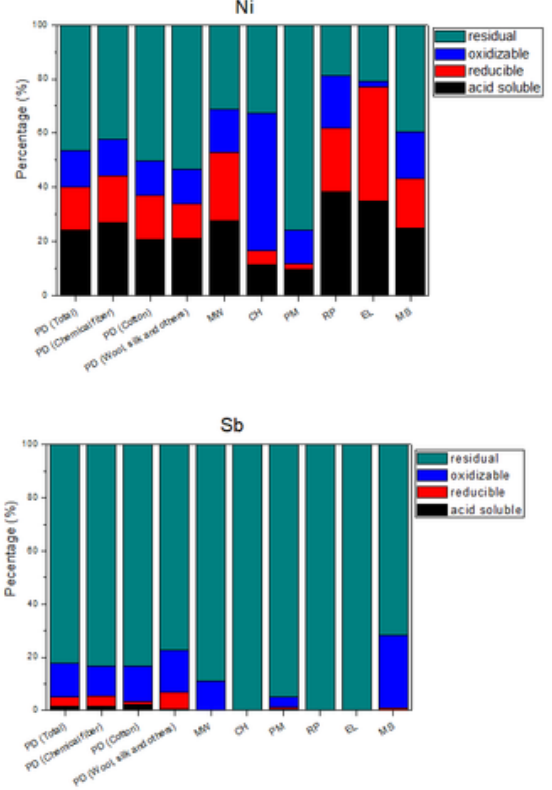

Zn

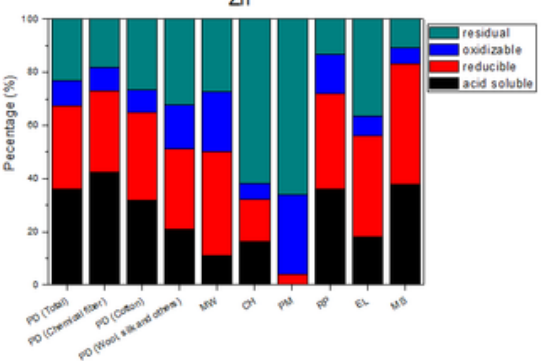

Figure 3

Percentage of heavy metal forms in industrial and municipal sewage sludge. PD, MW, CH, PM, RP, EL and MS represent printing and dyeing industry, metalworking industry, chemical industry, papermaking industry, rubber and plastic industry, electron industry and municipal sewage treatment plant, respectively. 


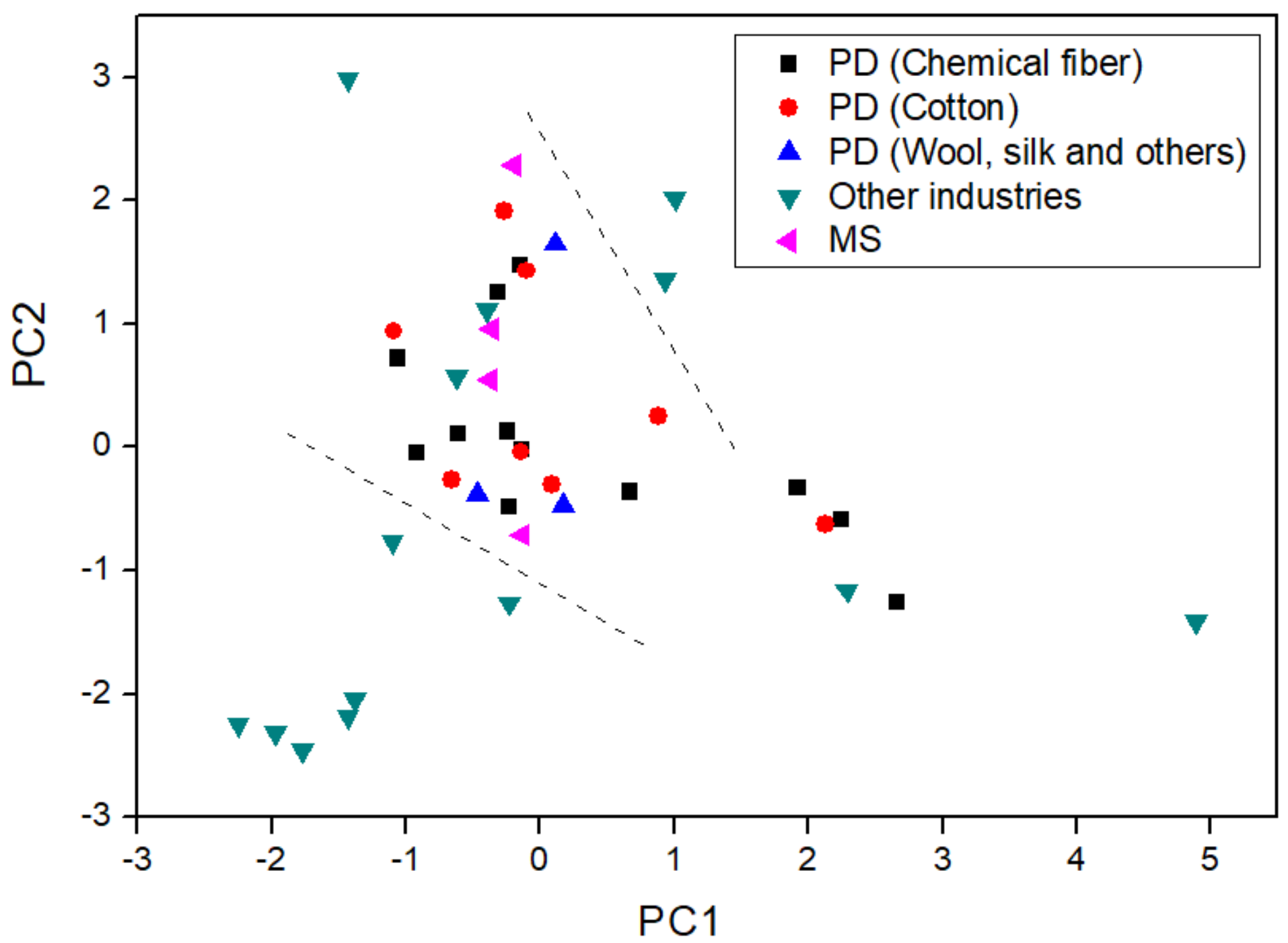

Figure 4

PCA of percentage of heavy metal contents in industrial and municipal sewage sludge. PD and MS represent printing and dyeing industry and municipal sewage treatment plant, respectively. 


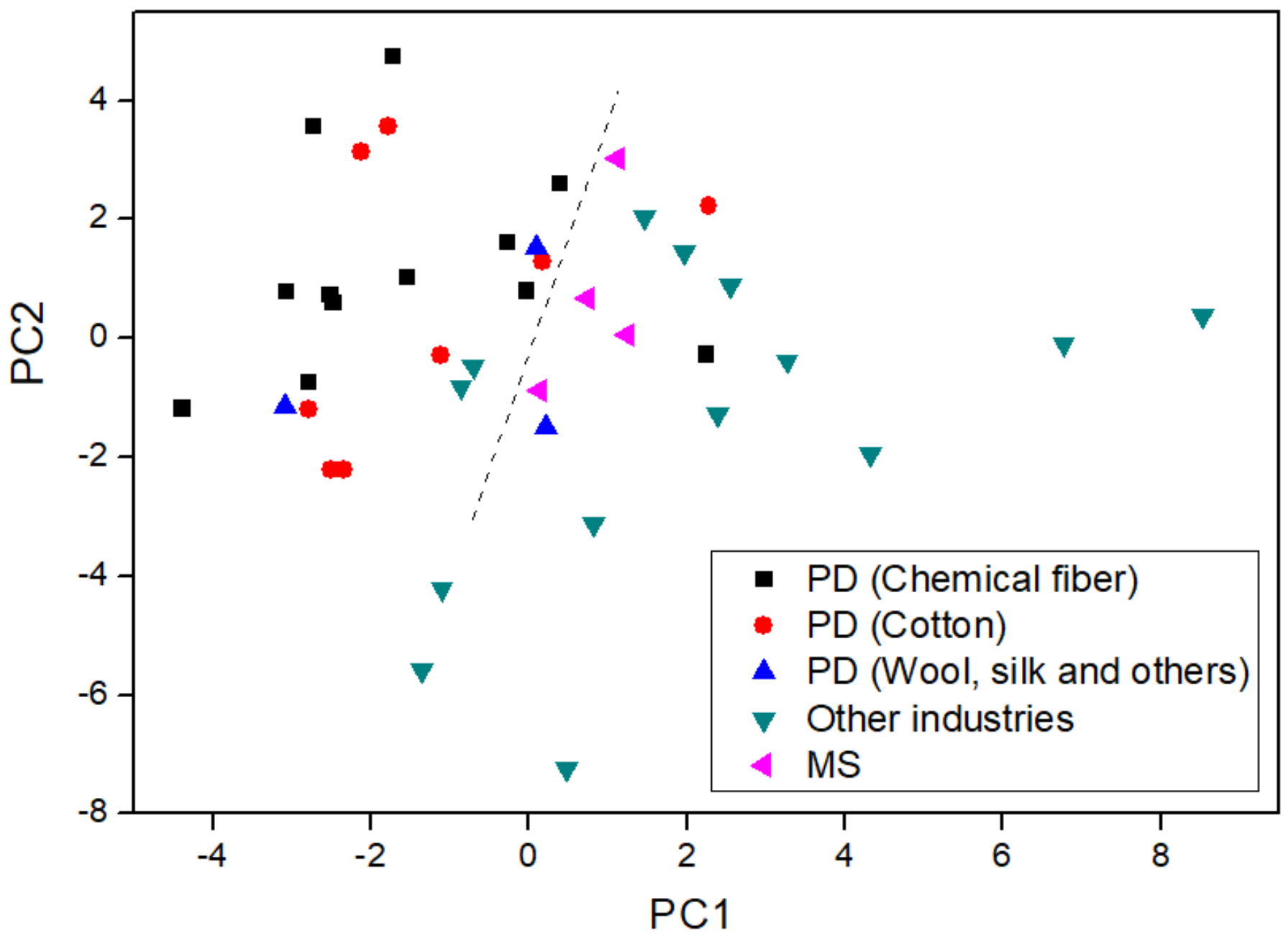

Figure 5

PCA of percentage of heavy metal forms in industrial and municipal sewage sludge. PD and MS represent printing and dyeing industry and municipal sewage treatment plant, respectively. 


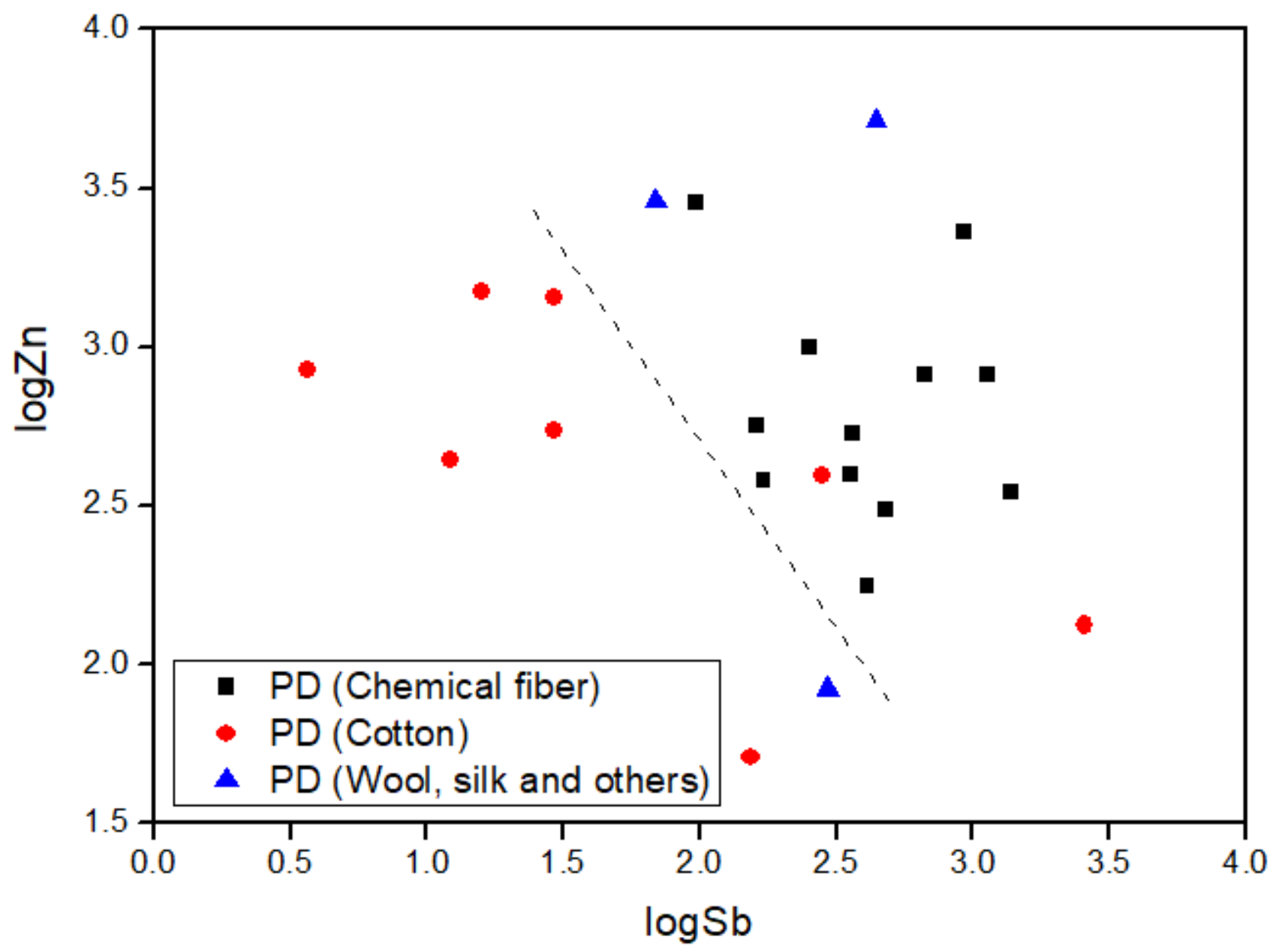

Figure 6

Biplot of characteristic heavy metals ( $\mathrm{Sb}$ and $\mathrm{Zn}$ ) in printing and dyeing sub-industries. PD represents printing and dyeing industry.

\section{Supplementary Files}

This is a list of supplementary files associated with this preprint. Click to download.

- SupportingInformation.docx 